\title{
Design and Development of Mini Tractor Operated Installer and Retriever of Drip Line
}

\author{
P.R. Balas ${ }^{1 *}$, K.B. Jhala ${ }^{1}$, J.M. Makavana ${ }^{2}$ and V.V. Agravat ${ }^{1}$ \\ ${ }^{1}$ Department of Farm Machinery and Power Engineering, ${ }^{2}$ Department of Renewable Energy \\ Engineering, CAET, JAU, Junagadh, Gujarat, India \\ *Corresponding author
}

\section{A B S T R A C T}

\begin{tabular}{|l|}
\hline K e y w o r d s \\
$\begin{array}{l}\text { Drip irrigation, Drip line, } \\
\text { Drip lateral, Installer, } \\
\text { Retriever, De-coiling, } \\
\text { Handling implement, Farm } \\
\text { equipment, Winder, Drip } \\
\text { tapes }\end{array}$ \\
\hline Article Info \\
\hline $\begin{array}{l}\text { Accepted: } \\
10 \text { July 2018 } \\
\text { Available Online: } \\
\text { 10 August } 2018\end{array}$ \\
\hline
\end{tabular}

\section{Introduction}

Drip irrigation is the drop by drop application of water directly to roots. It has little or no water losses through conveyance and the onfarm irrigation efficiency of a properly designed and managed drip irrigation system can be as high as 90 per cent, compared with 35 to 40 per cent efficiency of surface method of irrigation (Narayanmoorthy, 1997). The area covered under drip irrigation systems has, the largest area under drip irrigation include Rajasthan 1.68 Mha, Maharashtra 1.27 Mha, Andhra Pradesh 1.16 Mha, Karnataka 0.85 Mha, Gujarat 0.83 Mha and Haryana 0.57
Mha. The area under drip irrigation has shown higher growth in recent years, growing at a CAGR (Compound annual growth rate) of 9.85 per cent in the 2012-2015 period, while sprinkler irrigation has grown a pace of 6.60 per cent in the same time period. Overall, the area under micro-irrigation has grown at a CAGR of 7.97 per cent in this time frame (Anon., 2016a).

In field, drip line requires various field operations such as installation and retrieval of drip line. Installation and retrieval by mechanical method as well as manual method were used. Farmers have been using manual 
device for installation and retrieval operation, they were time consuming, laborious, boring, tedious and costly also. These operations need to be done carefully and skilfully to avoid the damages due to folding or twisting of tube during handling and to make the bundle suitable for proper storage. Therefore, the present study was carried out to developed and evaluates the performance of mini-tractor operated installer and retriever of the drip line with the following

\section{Literature review}

Zhu et al., (2004) developed an implement is mounted to the tractor using a three-point hitch and performs both functions of installation and retrieval of drip tapes in one unit. During the installation process, drip tapes are placed in shallow trenches cut by the $5 \mathrm{~cm}$ wide chisel and are covered with soil by 6.5 $\mathrm{cm}$ wide pneumatic wheels. The depth of drip tapes can be adjusted from 0 to $5 \mathrm{~cm}$ beneath the soil surface.

During the drip tape retrieval process, drip tapes are distributed evenly across rotating spools while any water in the tapes is squeezed out. The retrieval speed is adjusted by changing the tractor PTO (Power Take Off) speed. To retrieve excess disposable drip tapes, a special spool was developed to quickly remove the tapes from the unit. No tools are needed for either installing or removing drip tape spools.

Mathematical models were developed to calculate drip tape length, retrieving time, and spool sizes.

Taley et al., (2006) developed manual coiler and tested for its performance with $150 \mathrm{~m}$ long segment of drip lateral in the field and reported that overall performance of machine good in terms of field capacity, field efficiency, and reduction in cost.

\section{Materials and Methods}

A drip line installer and retriever were designed and developed to combine install and retrieve operations of drip line in one pass to ensure timeliness in making bundles of drip line. The drip line installer and retriever machine consist of a main frame with installer as well as retriever frame, hydraulic motor, press wheel, guide wheel, support wheel, power transmission system to provides power for installing and retrieving attachment, framework and three-point linkage unit. The components of drip line installer and retriever were designed and fabricated based on the parameters like functional requirements, engineering and general considerations.

\section{General consideration}

It should be simple in design, safe in operation and power requirement be met with mini tractor. It should install and retrieve drip line faster than the existing traditional methods.

\section{Assumptions considered in design}

The assumptions made in the design of installer and retriever of drip line are as follow:

No draft was included for installer and retriever of drip line attachment because it is semi mounted. The implement being semi mounted type, the draft requirement was considered to be negligible.

The power consumption by the device is very low within the capacity of available mini tractor.

It should install or retrieve three row of dripline at a time.

It should be simple in fabrication and easy to manufacture using locally available materials. 
All part can be easily assemble and dismantled for inspection and repair

\section{Development of major functional components of drip line installer and retriever}

The detailed design of the functional components and different mechanisms were carried out. The machine consists of a main frame with sub frames for installer as well as retriever, hydraulic pump, press wheel, guide wheel, support wheel, power transmission system to provides power to installing and retrieving attachment, framework and threepoint linkage unit. The basic emphasis was given on simplicity of fabrication, use of locally available material and minimum cost of fabrication. Ease of assembling and dismantling for repairs and inspection were duly considered. The design of following components was taken up:

\section{Main Frame}

Spool

Press Wheel

Guide Wheel \& shaft

Support Wheel

Depth Control Wheel (Fig. 1)

\section{Main Frame}

The main frame is meant for holding different components, which may be subjected to bending, tension, and vibrations. Two Lsections of $50^{\mathrm{x}} 50^{\mathrm{x}} 5 \mathrm{~mm}$ were welded together to form a square hallow pipe. This square hollow pipe was used to make square frame $1900 \mathrm{x} 900 \mathrm{~mm}$. This square frame used as a main frame for an according the components like sub frames, hydraulic pump, press wheel, guide wheel, transportation wheel, depth control wheel, power transmission system. The size of the fabricated frame is as shown in the Figure 2. Main frame is such that it can be divided into three parts.
Two end parts can be brought in line or can be pushed back side of the center part as per the requirement i. e. operation in field or transportation. The length $(1900 \mathrm{~mm})$ of the central part of the frame is equal to the width of the tractor $\left(1900^{\mathrm{x}} 900 \mathrm{~mm}\right)$ whereas the two side parts are $950 \times 900 \mathrm{~mm}$ each.

\section{Spool}

The spool (Fig. 3) consists of a shaft $(450 \mathrm{~mm}$ x $650 \mathrm{~mm}$ ) mounted on a spool supporting frame made from square pipe. The shaft is having fixed wheel of $900 \mathrm{~mm}$ on one side and a collapsible four bar attachment on the other side of the shaft. The shaft is mounted such that it acts as a cantilever having support of two bearing $(6209,45 \times 85 \times 19)$ on one side. The shaft is covered with baffle plates (4 plates, GI sheet, $3 \mathrm{~mm}$ thick, $650 \mathrm{~mm}$ x 20 $\mathrm{mm}$ ) and a mechanism to contract or expanded as per the requirement. Spool is mounted on the main frame with help of spool supporting frame. The height of spool supporting frame is $550 \mathrm{~mm}$ from main frame. The dimension of the drip line is an important factor in designing the diameter and width of the spool. Considering the standard dimensions of new drip line, the dimensions of the spool are kept as. In which $300 \mathrm{~mm}$ is the diameter of spool, $200 \mathrm{~mm}$ is assumed as thickness of drip line bundle with $150 \mathrm{~mm}$ (50 mm freeboard +100 $\mathrm{mm}$ passage) freeboard. A sprocket having 14 teeth mounted on the shaft of the pedicle block bearing for transmitting the power.

\section{Press wheel}

The press wheels were fabricated using MS hollow pipe of $250 \mathrm{~mm}$ diameter and $30 \mathrm{~mm}$ length having $3 \mathrm{~mm}$ thickness. Two circular plates of $3 \mathrm{~mm}$ thickness and $310 \mathrm{~mm}$ diameter were welded on each side of the hollow pipe as above. This creates a groove (Fig. 4) of $30 \mathrm{~mm}$ on each end. Three such wheels were fabricated. All the three wheels 
were attached to the main frame. The brackets were fixed with bolts and nut such that they allowed the movement of threaded rod. Iron plate $500 \mathrm{~mm}{ }^{\times} 30 \mathrm{~mm} \times 5 \mathrm{~mm}$ was bent in Cshape, and a $10 \mathrm{~mm}$ hole was drilled at both ends, $C$ shape iron plate and wheel were joined by means of nut and bolt (Fig. 4). Size of bolt used is $100 \mathrm{~mm}$ length and $10 \mathrm{~mm}$ diameter. Threaded iron rod having diameter $25 \mathrm{~mm}$ and length $(350 \mathrm{~mm})$ with two nuts for locking (Fig. 4). One end of threaded rod was welded on middle part of $\mathrm{C}$-shape the other end was attached to remove moulded knob by means of a nut (Fig. 4).

A pipe having $30 \mathrm{~mm}$ diameter and $50 \mathrm{~mm}$ length was welded with L- shaped plate which is directly attached to main frame by means of nut and bolt. Iron rod was threaded throughout its length. The depth of press wheel can be adjusted by means of two nuts. Flexible PVC pipe of $350 \mathrm{~mm}$ diameter and $30 \mathrm{~cm}$ length was joined by means of welding with $\mathrm{C}$ shaped iron plate with two extensions (Fig. 4). Press wheel is attached at rear side of the implement by nut-bolt (100 mm length and 10 $\mathrm{mm}$ diameter) such that it travels near the crop row. During installation of drip line, it passes through the groove of press wheel and a straight row of drip line is maintained through press wheel near the crop row.

\section{Guide wheel and shaft}

The lateral guiding wheel is a simple nonpowered, freely rotating wheel mounted on a shaft called guiding wheel shaft. The guide wheels were fabricated using MS hollow pipe of $90 \mathrm{~mm}$ diameter, $30 \mathrm{~mm}$ length having 3 $\mathrm{mm}$ thickness (Fig. 5). Two circular plates of $3 \mathrm{~mm}$ thickness and $150 \mathrm{~mm}$ diameter were welded on each side of the hollow pipe as mentioned above. In center of circular plate, a hole of $30 \mathrm{~mm}$ diameter was drilled. This creates a groove (Fig. 6) of $30 \mathrm{~mm}$ on each end. Three such wheels were fabricated. All the three wheels were attached to the spool supporting frame. Guide wheel shaft has 15 $\mathrm{mm}$ diameter and $650 \mathrm{~mm}$ length, and length is selected according to length of spool. Two stoppers on shaft specifies the limits of movement of wheel on the shaft. The limit is adjusted by means of stopper as above. Shaft is welded to rectangular plate $(70 \times 50 \mathrm{~mm})$. Rectangular plate is directly attached to spool supporting frame by means of nut-bolt (Fig. 7).

Fig.1 Developed machine

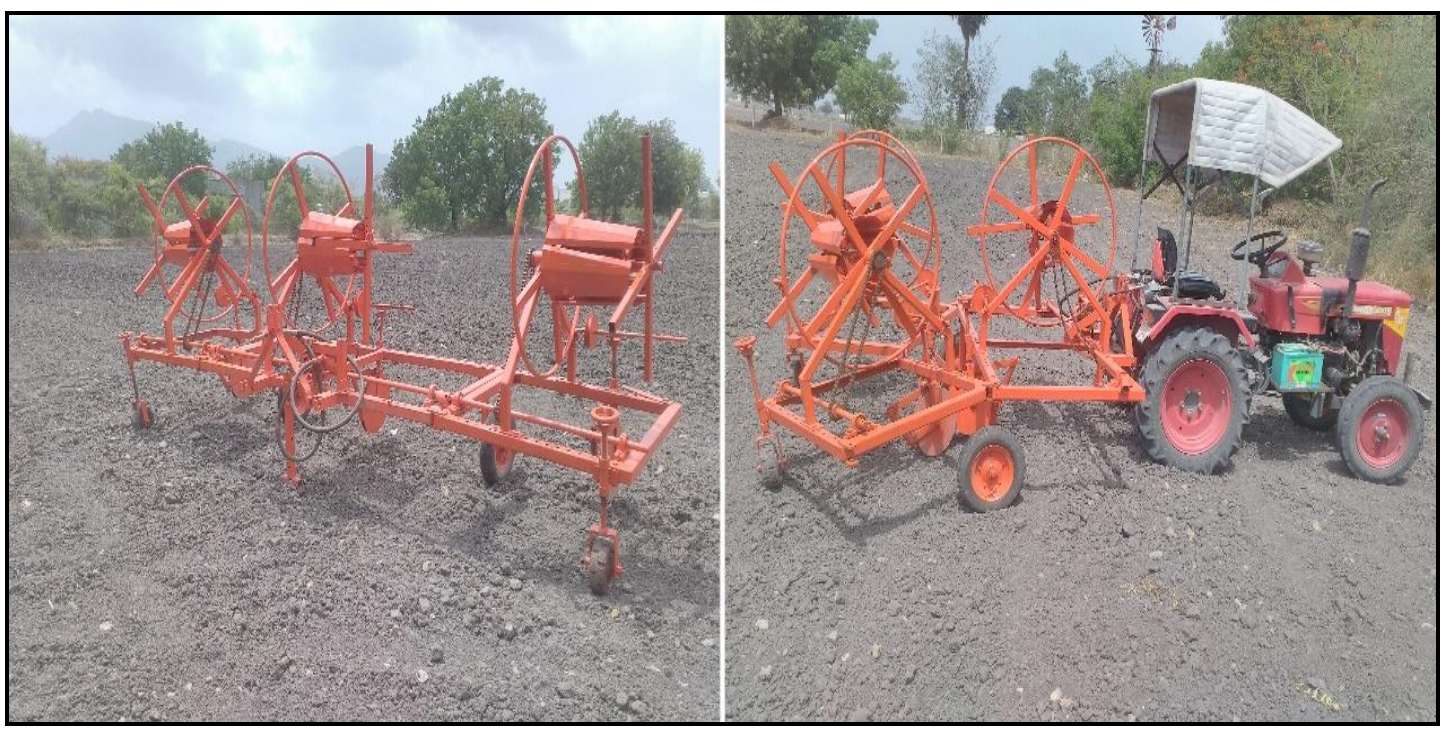


Fig.2 Detailed drawing of main frame

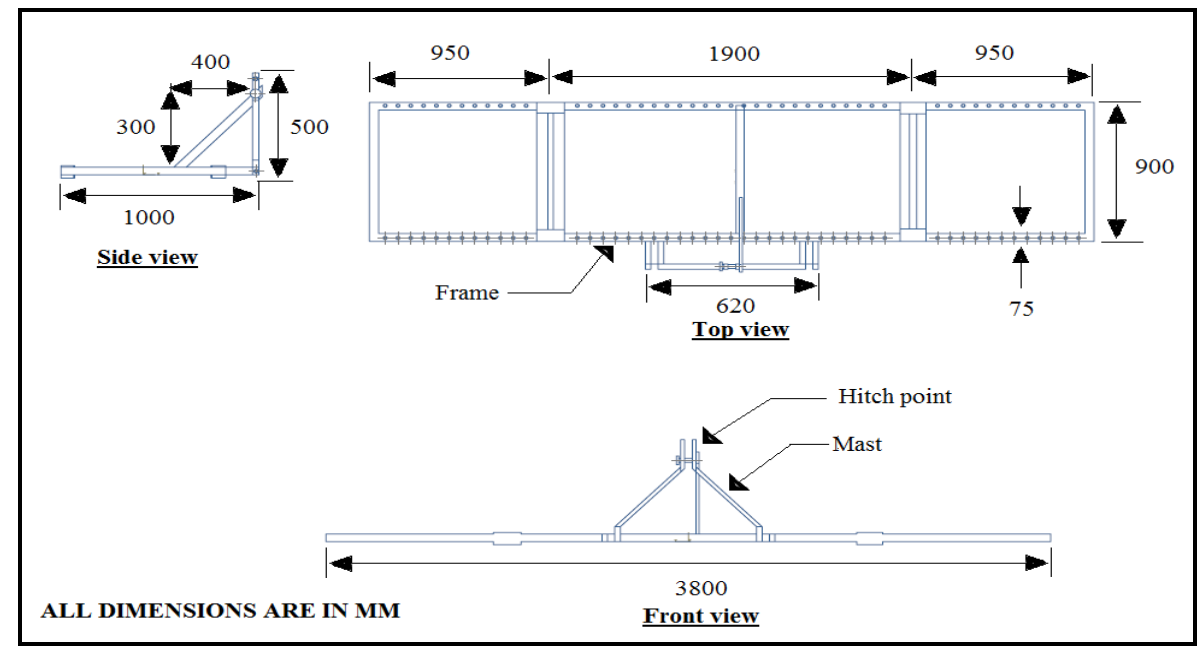

Fig.3 Fabricated view of spool

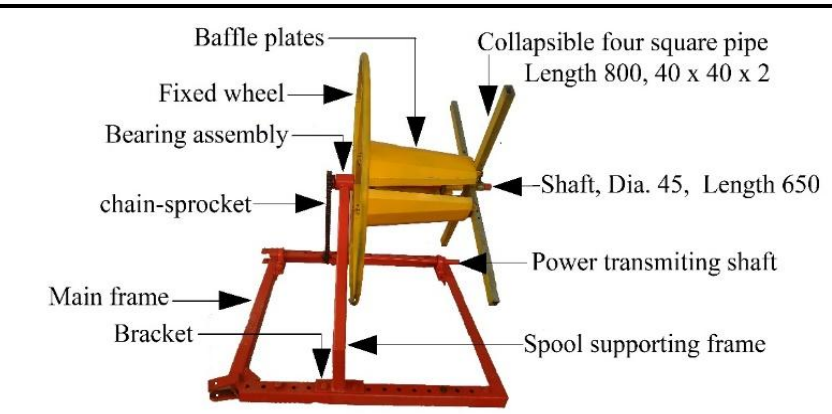

ALL DIMENSIONS ARE IN MM

Fig.4 Detailed drawing of press wheel

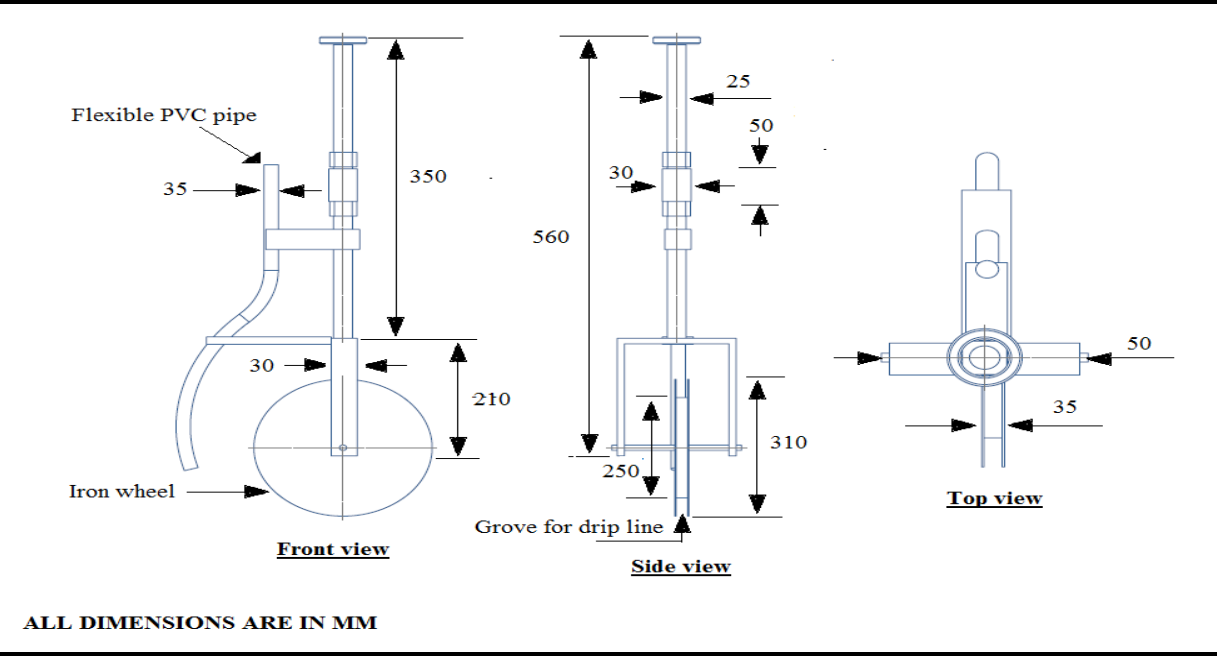


Fig.5 Fabricated view of press wheel

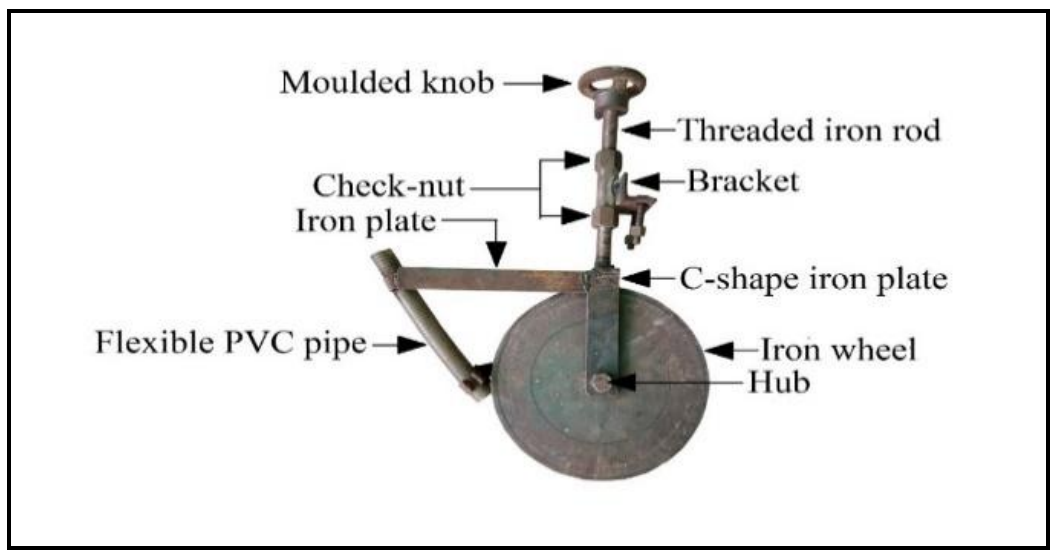

Fig.6 Detail dimension of guide wheel and shaft

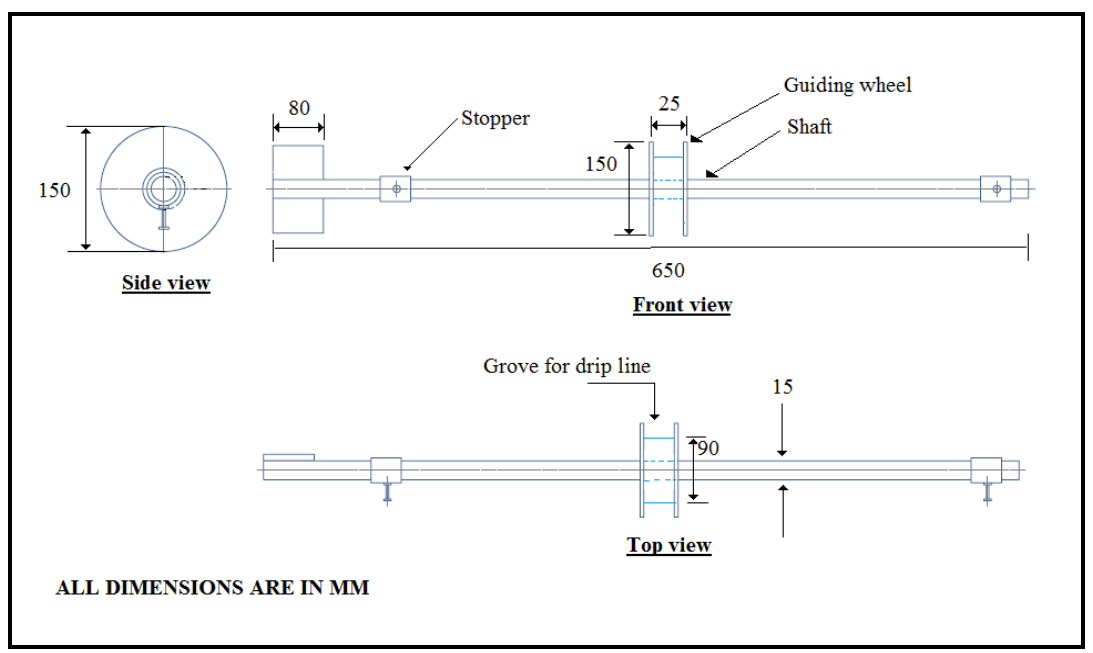

Fig.7 Fabricated view of guiding wheel and shaft
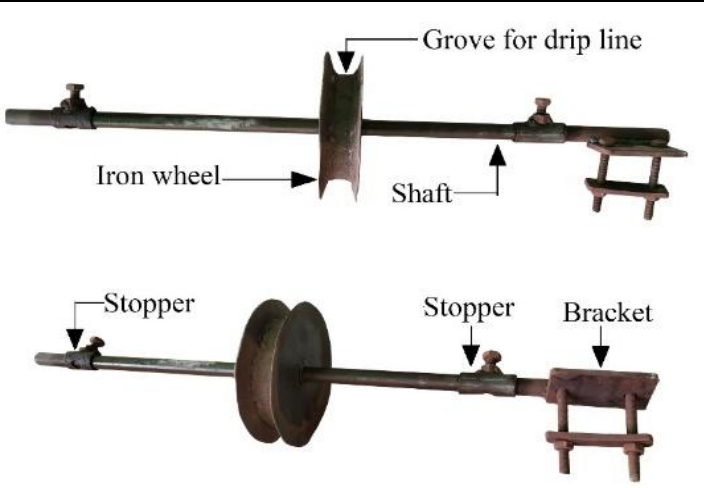
Fig.8 Detailed drawing of transportation wheel

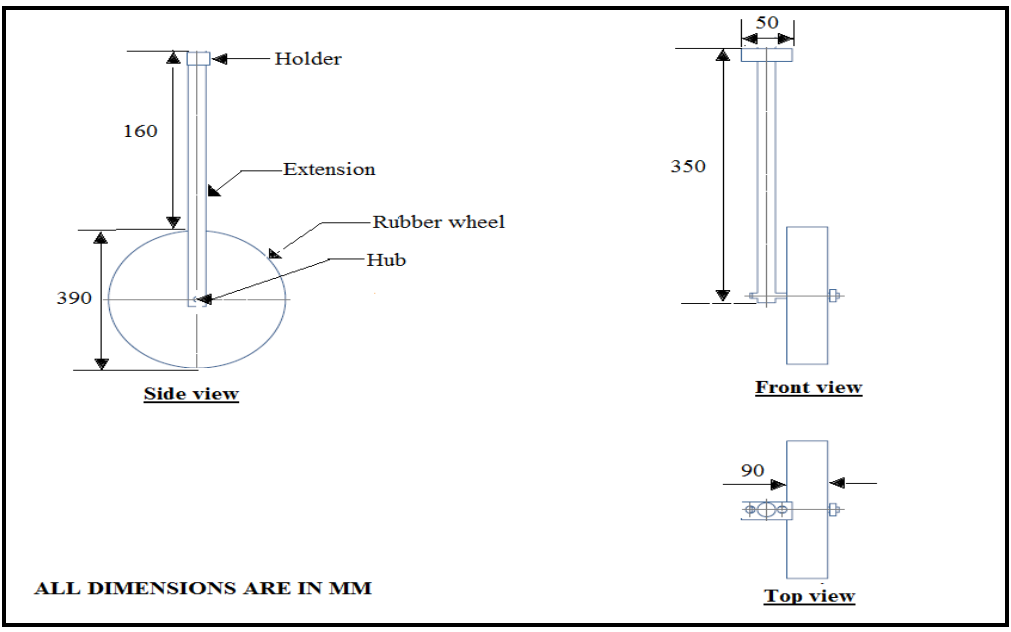

Fig.9 Fabricated view of transportation wheel

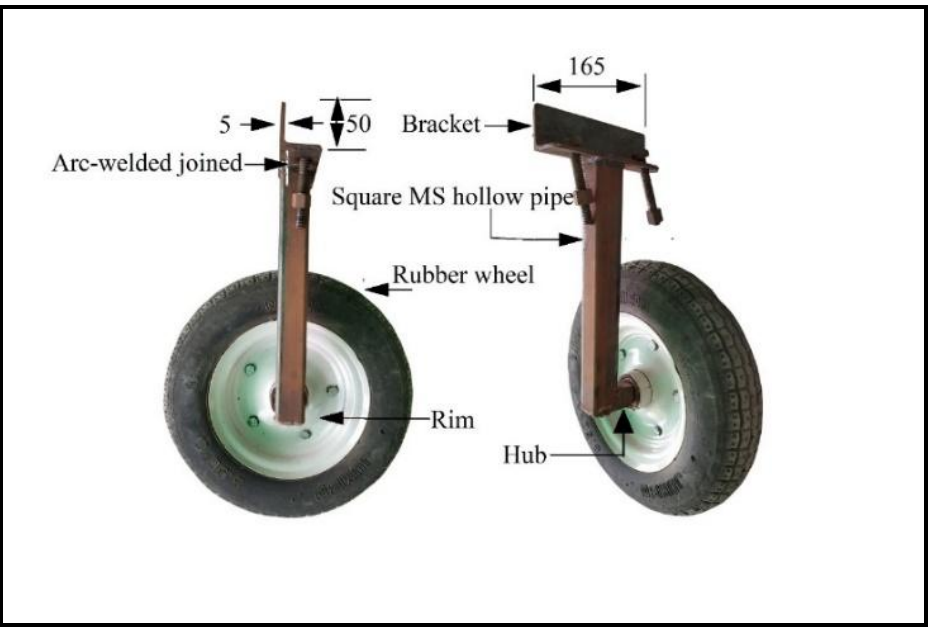

Fig.10 Detailed drawing of depth control wheel

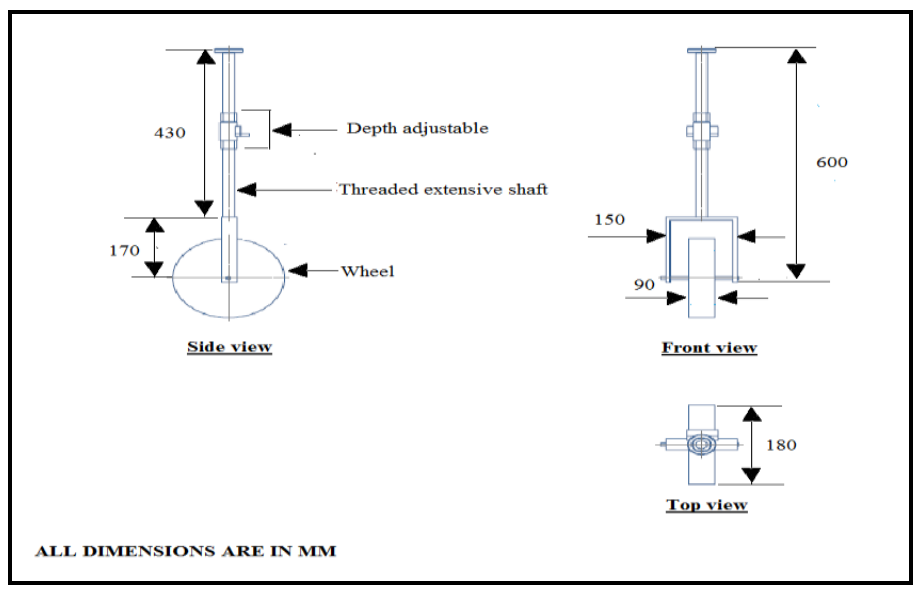


Fig.11 Febricated view of depth control wheel

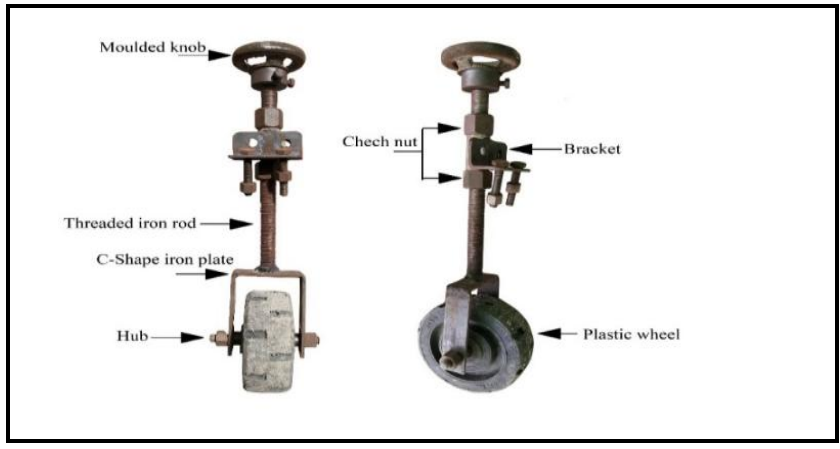

Fig.12 Power transmission unit of drip line installer and retriever

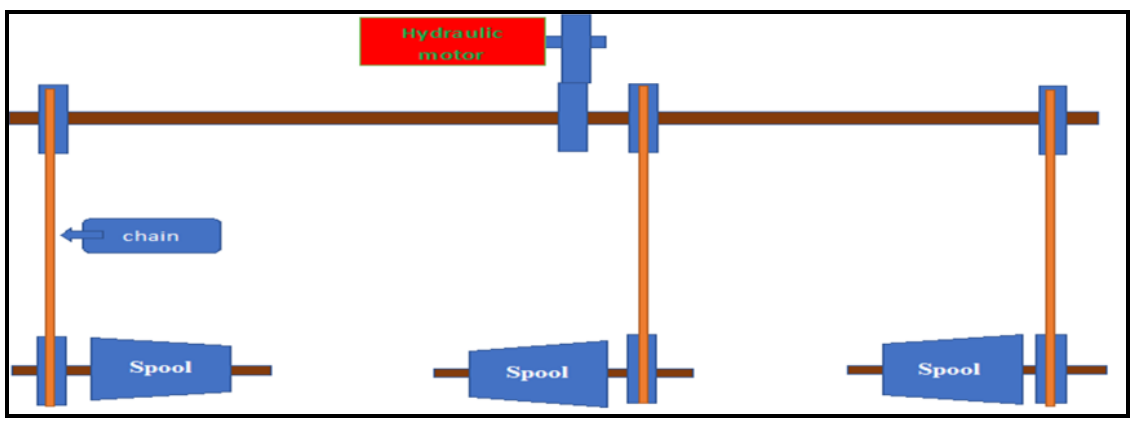

Fig.13 Developed device (a) \& (b)

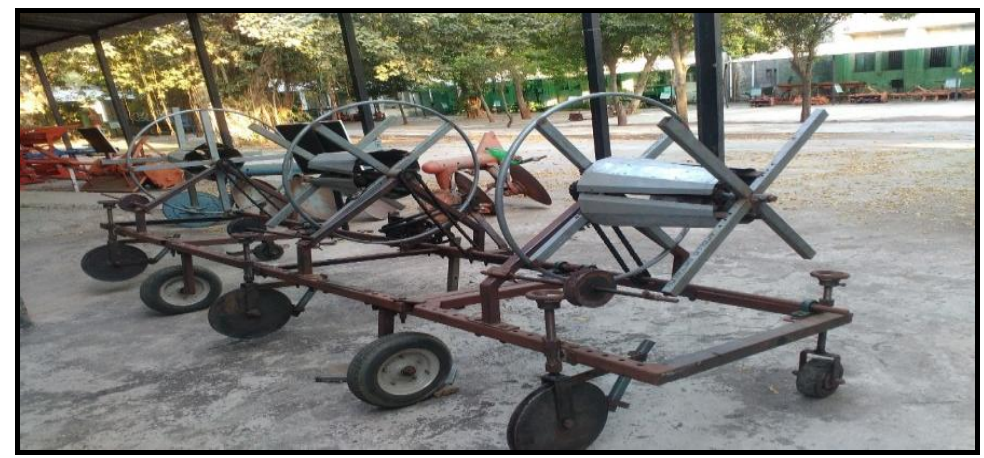

(a)

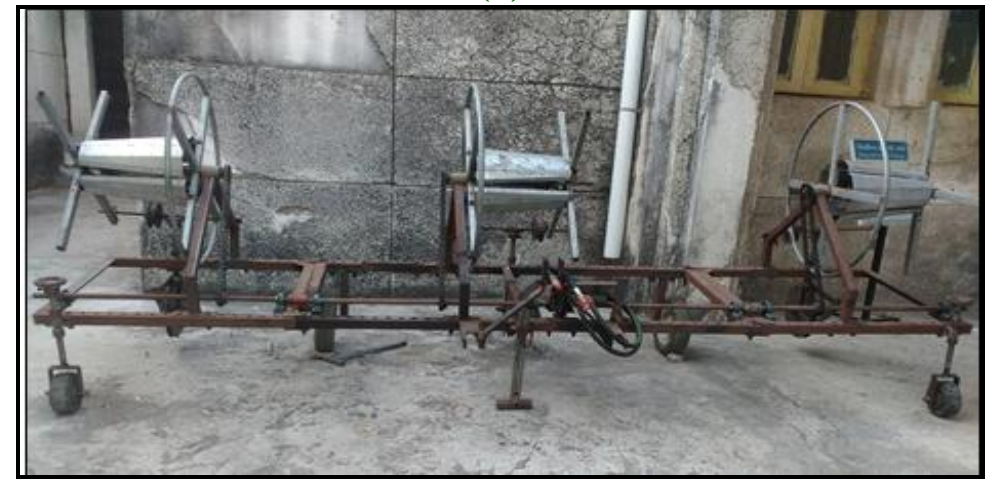

(b) 
Table.1 Detailed specifications of installing and retrieving attachment to main frame

\begin{tabular}{|c|c|c|}
\hline Sr. & Particulars & Specifications \\
\hline 1 & Name of implement & Installer and retriever of drip line \\
\hline \multirow[t]{3}{*}{2} & \multicolumn{2}{|l|}{ Type of hitch and its detail } \\
\hline & Linkage & 3 - Point hitch system \\
\hline & Power source & Hydraulic motor \\
\hline \multirow[t]{5}{*}{3} & \multicolumn{2}{|l|}{ Overall Dimensions } \\
\hline & Length, mm & 3800 \\
\hline & Width, mm & 900 \\
\hline & Height, mm & 1520 \\
\hline & Weight, kg & \\
\hline \multirow[t]{5}{*}{4} & \multicolumn{2}{|l|}{ Frame } \\
\hline & Material of fabrication & $\begin{array}{l}\text { Mild Steel }(\mathrm{L}-\text { channel size: } 65 \mathrm{~mm} \\
\times 65 \mathrm{~mm} \times 6 \mathrm{~mm}) \\
\text { Three point hitch }(75 \mathrm{~mm} \times 5 \mathrm{~mm})\end{array}$ \\
\hline & Length, $\mathrm{mm}$ & 3800 \\
\hline & Width, mm & 900 \\
\hline & Height, mm & 500 \\
\hline \multirow[t]{8}{*}{5} & \multicolumn{2}{|l|}{ Transportation Wheel } \\
\hline & Material of fabrication & Rubber wheel with extension \\
\hline & Diameter of wheel, mm & 390 \\
\hline & Thickness of wheel, mm & 90 \\
\hline & Length of extension, $\mathrm{mm}$ & 350 \\
\hline & Diameter of handle wheel, mm & 110 \\
\hline & $\begin{array}{l}\text { Dimension of wheel holding plate, } \\
\mathrm{mm}\end{array}$ & $165 \times 50$ \\
\hline & No. of transportation wheel & 2 \\
\hline \multirow[t]{7}{*}{6} & \multicolumn{2}{|l|}{ Installer/Retriever } \\
\hline & Material of fabrication & Mild Steel \\
\hline & $\begin{array}{l}\text { Nos. of Installer / retriever on } \\
\text { frame }\end{array}$ & 3 \\
\hline & Height, $\mathrm{mm}$ & 1000 \\
\hline & Diameter, mm & 90 \\
\hline & Thickness, mm & 55 \\
\hline & $\begin{array}{l}\text { Spacing between Installer / } \\
\text { retriever on frame, } \mathrm{mm}\end{array}$ & 1200 \\
\hline \multirow[t]{6}{*}{7} & \multicolumn{2}{|l|}{ Press wheel } \\
\hline & Material of fabrication & Mild Steel \\
\hline & $\begin{array}{l}\text { Length of extension of press } \\
\text { wheel, } \mathrm{mm}\end{array}$ & 350 \\
\hline & Diameter of wheel, mm & 330 \\
\hline & Diameter of wheel grove, $\mathrm{mm}$ & 35 \\
\hline & Thickness of wheel plate, $\mathrm{mm}$ & 3 \\
\hline
\end{tabular}




\begin{tabular}{|c|c|c|}
\hline & Diameter of wheel shaft, $\mathrm{mm}$ & 25 \\
\hline & Width of groove on wheel & 30 \\
\hline & Thickness of the disc, mm & 28 \\
\hline & Diameter of PVC pipe, $\mathrm{mm}$ & 35 \\
\hline & Length of PVC pipe, mm & 300 \\
\hline & No. of Press wheel & 3 \\
\hline 8 & Guide wheel & \\
\hline & Material of fabrication & Mild Steel \\
\hline & Length of guide wheel shaft, $\mathrm{mm}$ & 65 \\
\hline & Diameter of guide wheel, mm & 150 \\
\hline & Diameter of wheel grove, $\mathrm{mm}$ & 1000 \\
\hline & Thickness of wheel plate, $\mathrm{mm}$ & 3 \\
\hline & Diameter of wheel shaft, mm & 15 \\
\hline & Depth of wheel groove, mm & 5 \\
\hline & Length of holding plat, mm & 50 \\
\hline & No. of guide wheel & 3 \\
\hline 9 & Power transmitting shaft & \\
\hline & Material of fabrication & Mild steel rod \\
\hline & Length, mm & 750 \\
\hline & Diameter, mm & 45 \\
\hline 10 & Chain and sprocket mechanism & \\
\hline & Type & Pintle chain \\
\hline & Width, mm & 10 \\
\hline & Length, mm & 1624 \\
\hline & Thickness, mm & 3 \\
\hline & Pitch, mm & 16 \\
\hline & Velocity ratio & $1: 1$ \\
\hline 11 & Spur gear & \\
\hline & Material of fabrication & Cast iron \\
\hline & Velocity ratio & $1: 2$ \\
\hline 12 & Pedestal block bearing & \\
\hline & Material of fabrication & Casting with press fitted bearing \\
\hline & Diameter, mm & 46 \\
\hline & Length, mm & 35 \\
\hline & Height, mm & 70 \\
\hline
\end{tabular}

\section{Transportation wheel}

As the name suggest these wheels are meant for transportation. The base components consist of a rubber tire along with a rim (Fig. 8 ). This is once again attached with iron member through a bearing and nut and bolt.
The iron member is made up of square MS hollow pipe $30 \times 30 \times 3 \mathrm{~mm}$ and having bosh over which the bearing is fitted. The length of iron member that line vertical is $350 \mathrm{~mm}$ (Fig. 8). A bracket to attach it with the main frame is made up of MS angle $50 \times 50 \mathrm{~mm}$ and 165 mm length (Fig. 8). Two bolts along with nuts 
are provided. The hole for same are made as show in Figure 8. Influence pressure of this rubber wheel was $50 \mathrm{~kg} / \mathrm{cm}^{2}$. It was supposed that the weight of the machine with full load is too high for efficient work. To reduce the work load of tractor two transport wheels were provided to the machine. The height of the machine from the ground was fixed. Maximum height facilitates easy transportation of the machine, work just like a tractor. On the field application the load is distributed between the hydraulic of the tractor and the two wheels which also reduce the effort of tractor.

\section{Depth control wheel}

The depth control wheel consists of a plastic wheel with threaded extension iron rod. The plastic wheel having $180 \mathrm{~mm}$ diameter and 90 mm width was readily available (Fig. 10), it was selected. All the two wheels were attached to the main frame. The brackets were fixed with bolts and nut such that they allowed the movement of threaded rod. Iron

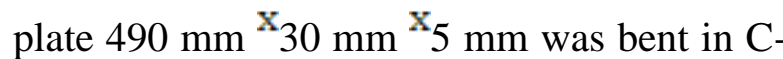
shape, and a $20 \mathrm{~mm}$ hole was drilled at both ends, C shape iron plate and wheel were joined by means of nut and bolt (Fig. 10). Size of bolt used is $80 \mathrm{~mm}$ length and $25 \mathrm{~mm}$ diameter. Threaded iron rod having diameter $25 \mathrm{~mm}$ and length $(350 \mathrm{~mm})$ with two nuts for locking. One end of threaded rod was welded on middle part of $\mathrm{C}$-shape the other end was attached to remove moulded knob by means of a nut (Fig. 10). A pipe having $30 \mathrm{~mm}$ diameter and $50 \mathrm{~mm}$ length was welded with L- shaped plate which is directly attached to main frame by means of nut and bolt (Fig. 10). Iron rod was threaded throughout its length. The depth of depth wheel can be adjusted by means of two nuts. Depth wheel is attached at front side with both ends of main frame of the implement by nut-bolt (100 $\mathrm{mm}$ length and $10 \mathrm{~mm}$ diameter). These wheels are provided to maintain the depth of laying down the lateral line a required level. The pair of wheels was having the adjustment for controlling the depth. It consisted of threaded iron rod which had provision of nut and bolt arrangement for controlling the depth of penetration of machine.

\section{Power transmission unit of drip line installer and retriever}

Power transmitted from hydraulic motor to main shaft through spur gear of $1: 2$ ratio. So that hydraulic motor transmits $17-45 \mathrm{rpm}$ at different three levels, corresponding power transmission to main shaft was 35-89 rpm. Power transmission shaft is connected to spool by chain and sprocket transmission system, which transmits $35-90 \mathrm{rpm}$ at $1: 1$ ratio. Power transmission system include hydro motor, spur gears, chain and sprocket and pedestal block bearing which is included in this section. Schematic diagram of power transmission is shown in Figure 11.

\section{Fabricated installing and retrieving attachment to main frame}

Design and developed installing and retrieving attachment to main frame, its design drawing and specifications of all units are shown in following Figure 8 (a \&b) and Table 1 respectively.

\section{References}

Anonymous. 2016a. Agriculture in India. Available at https://en.wikipedia.org/ wiki/ Agriculture_in India/ accessed on $2^{\text {nd }}$ August, 2017.

Narayanamoorthy, A. 1997. Economic viability of drip irrigation: An empirical analysis from Maharashtra. Indian Journal of Agricultural Economics. 52(4): 728-739.

Narayanmoorthy, A. 2004. Drip and sprinkler irrigation in India: Benefits, potential 
and future directions. Water Policy. 26(1): 253-265.

Narayanmoorthy, A. 2010. Economics of drip irrigated cotton: A synthesis of four case studies. Indian Journal of Agricultural Economics. 58(4): 37-50.

Taley, S. S., Bhende. S. M., and Tale, V. P. (2006). Testing, evaluation and modification of manual coler for drip lateral. AMA, 37(1): 75-79

Zhu, H., Butts, C. L., Lamb, M. C. and Blankenship, P. D. 2004. An implement to install and retrieve surface irrigation laterals. Applied Engineering in Agriculture. 20(1): 17-23.

\section{How to cite this article:}

Balas, P.R., K.B. Jhala, J.M. Makavana and Agravat, V.V. 2018. Design and Development of Mini Tractor Operated Installer and Retriever of Drip Line. Int.J.Curr.Microbiol.App.Sci. 7(08): 1566-1577. doi: https://doi.org/10.20546/ijcmas.2018.708.179 